\title{
Simplified graphical tools for assessing flood-risk change over large flood-prone areas
}

\author{
F. Carisi, A. Domeneghetti, and A. Castellarin \\ School of Civil, Chemical, Environmental and Materials Engineering, DICAM, University of Bologna, \\ Bologna, Italy \\ Correspondence to: F. Carisi (francesca.carisi@unibo.it)
}

Received: 11 March 2015 - Accepted: 11 March 2015 - Published: 11 June 2015

\begin{abstract}
We propose and investigate the reliability of simplified graphical tools, which we term Hypsometric Vulnerability Curves, HVCs, for assessing flood vulnerability and risk over large geographical areas and for defining sustainable flood-risk mitigation strategies. These curves rely on the use of inundation scenarios simulated by means of quasi-two-dimensional (quasi-2-D) hydrodynamic models that reproduce the hydraulic behaviour of the floodable area outside the main embankment system of the study river reach. We present an application of HVCs constructed on the basis of land use and census data collected during the last 50 years for assessing the recent dynamics of the flood vulnerability and risk over a large floodable area along a $350 \mathrm{~km}$ stretch of the River Po (Northern Italy). We also compared the proposed simplified approach with a traditional approach based on simulations performed with the fully-2-D hydrodynamic model TELEMAC-2-D, a widely employed and well-known 2-D finite-element scheme. By means of this comparison, we characterize the accuracy of the proposed simplified approach (i.e. quasi-2-D model and HVCs) for flood-risk assessment over large geographical areas and different historical land-use scenarios.
\end{abstract}

\section{Introduction}

According to the Emergency Events Database (EM-DAT dataset; http://www.emdat.be), the most impacting natural disasters in terms of number of people affected and economic damages are the freshwater floodings (such as river floods, flash floods, urban inundation due to drainage problems, etc.), and the flood-related losses increased enormously in the last half century. The scientific literature reports many studies that analyse the main drivers of this increase, but current research on socio-economic factors seems to identify the evolution of floodplains' exposure to floods as the most responsible factor that caused the growth of flood damages over the time period 1970-2006 (Barredo, 2009). Many other analyses about historical data agree with Barredo (2009), confirming the key-role played by economic and social development of flood-prone areas in the increase of flood losses during last decades (see e.g. Di Baldassarre et al., 2013, and references therein).

Under this premise, the definition of a robust large-scale flood-risk mitigation strategy requires us to take into account the interaction between social and hydrological factors that characterize a specific area and to adopt holistic approaches for assessing flood risk and its evolution in time. To this aim, we propose an approach based on simplified hydrodynamic models (i.e. quasi-two-dimensional, quasi-2-D) for assessing flood-risk over large geographical areas. We present an application of the proposed approach for quantifying floodrisk evolution during the last five decades (from 1954 to $2008)$ in a large flood-prone area $\left(\sim 6100 \mathrm{~km}^{2}\right)$ along the middle-lower portion of the Po river (Northern Italy), which we validate against traditional flood-risk assessment methods based on the use of fully-two-dimensional (fully-2-D) hydrodynamic models.

\section{Flood risk assessment}

\subsection{Traditional approach to flood risk assessment}

As inundation processes on floodplains have a markedly twodimensional (2-D) nature, the traditional approach to flood risk assessment resorts to the application of 2-D models for 
a quantification of hydraulic hazards. Based on topographic information, boundary and initial conditions and different mathematical and numerical schemes, 2-D models reproduce the inundation processes, simulating various flood intensity indicators such as water depth, flow velocity and dynamics of the flooding front.

The output of such models for reference inundation scenarios or sequences of hydraulic loads that are stochastically generated within a Monte Carlo framework (see e.g. Vorogushyn et al., 2010) are then used to assess the expected amount of economic damages in the study area. The scientific literature reports a wide set of depth-damage curves, in which the percentage of damage of a specific asset is related to the water depth. They are constructed on empirical damage data (i.e. historical inundations) or using expert judgment and synthetic analysis and refer to different applications contexts, diverse categories of buildings (i.e. residential, commercial, industrial, etc.; see e.g. Thieken et al., 2008) and the effect of factors which may influence the expected damages (e.g. contamination, levels of private precaution, etc.; see e.g. Kreibich et al., 2010).

Considering the traditional approach briefly recalled above, despite the high reliability of state-of-the-art fully2-D hydraulic models, and although these models are not necessarily slower in terms of computation time than simpler models, their implementation requires difficult numerical solutions and time consuming pre-processing steps (Falter et al., 2012, and references therein). This complexity is not compensated in terms of accuracy, when compared to less complex schemes in terms of inundation extent and risk estimates (see e.g., Castellarin et al., 2011b and references therein).

\subsection{A simplified approach for assessing flood risk over large geographical areas}

Due to the limitations of the traditional procedure over a large-scale analysis, outlined in Sect. 2.1 , we propose a simplified hydraulic approach in order to define a concise yet reliable methodology for flood risk assessments over large spatial areas. This approach consists of the development of an inundation scenario computed through a simplified quasi-2-D hydraulic model, that is a model combining 1-D river networks, for simulating the channels and the unprotected lateral floodplains, with hydraulically interconnected storage areas that reproduce the dyke-protected floodplains and the flood-prone areas outside the main embankment system (these latter named compartments hereinafter; see e.g. Castellarin et al., 2011a). The output of the model is then combined with graphical flood-vulnerability indexes described below, which are particularly suitable for large spatial scale assessments, and allows us to study the evolution in time of flood exposure, flood risk and economic damages.

The graphical tools we propose describe the floodvulnerability within each floodable compartment located out- side the embankment by combining land-use information (i.e. urban settlements, industrial or rural areas) with a digital description of the compartment topography. In particular, for each compartment and the land-use class of interest (e.g. urban and residential areas) the graphical tool reports on the $x$ axis the area of land-use class below the elevation reported on the $y$ axis (i.e. the empirical cumulative distribution function of the elevation of a given land-use class). We term these graphical tools Hypsometric Vulnerability Curves (HVCs). Once constructed the HVCs for each floodable area and land-use of interest, we assign an economic value to the elements-at-risk and we estimate the expected flood damages combining a depth-damage curve with the previously defined HVCs.

An example of potential damage computation is reported in Fig. 1. Let us focus for instance on urban areas, the maximum water level associated with a given inundation scenario may be reported on the urban-area HVC as a horizontal line (blue dashed line in Fig. 1b), which provides an indication of the extent of the flooded urban area $\left(\mathrm{A}_{\text {tot }}\right.$ in Fig. 1b). A depth-damage curve (Fig. 1a) can be used for associating the amount of damage to urban settlements $(D$ in $\%)$ with water depth $(h)$. Depth-damage curve also provides a waterdepth value $\left(h_{100}\right.$ in Fig. 1a) beyond which the percent of damage is equal to $100 \%$ (the overall economic value of the flooded buildings). Under a given inundation scenario, $\mathrm{A}_{100}$ in Fig. $1 \mathrm{~b}$ represents the portion of urban area for which simulated inundation water depths are higher than $h_{100}$. For this portion of urban area the flood damage, $D_{100}$, can be computed as:

$D_{100}=E \cdot \mathrm{A}_{100}$

where $E\left[€ \mathrm{~m}^{-2}\right]$ indicates the overall average economic value of residential buildings in the compartment. For the remaining portion of the flooded urban areas in the compartment (i.e. from $\mathrm{A}_{100}$ to $\mathrm{A}_{\text {tot }}$ in Fig. 1b) the flood damage $D_{h}$ is

$D_{h}=\int_{\mathrm{A}_{100}}^{\mathrm{A}_{\mathrm{tot}}} E \cdot d[h(\mathrm{~A})] \mathrm{dA}$

where $d(\cdot)$ represents the depth-damage curve as a function of $h(\mathrm{~A})$, that is the simulated water depth associated with $A \in\left[\mathrm{A}_{100}, \mathrm{~A}_{\text {tot }}\right]$ through the HCV. According to Eq. (1) and (2), the total direct damage in the compartment $D$ can be calculated as

$D=D_{100}+D_{h}$ 
a) Depth-damage curve

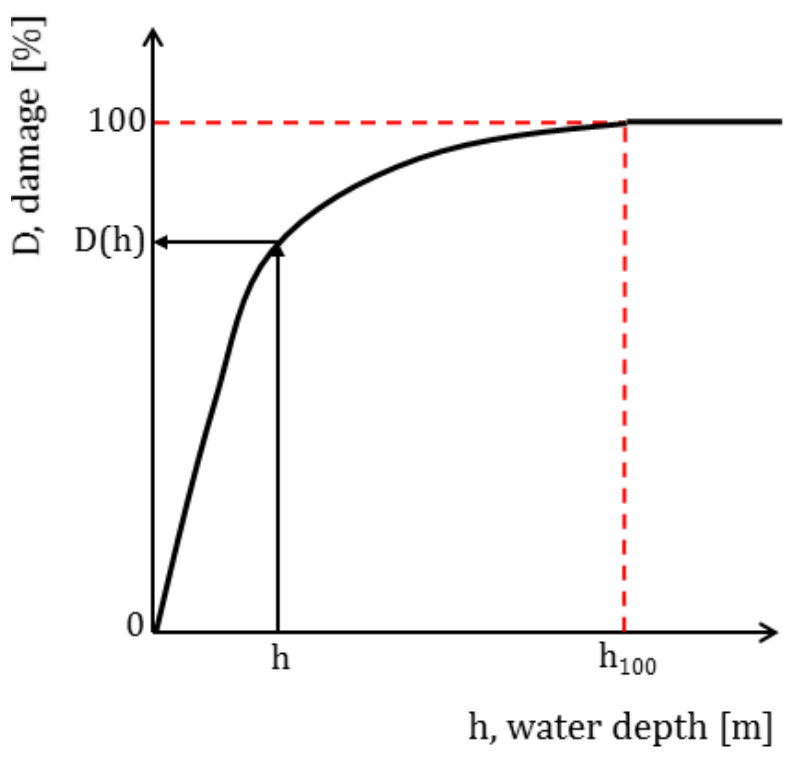

b)

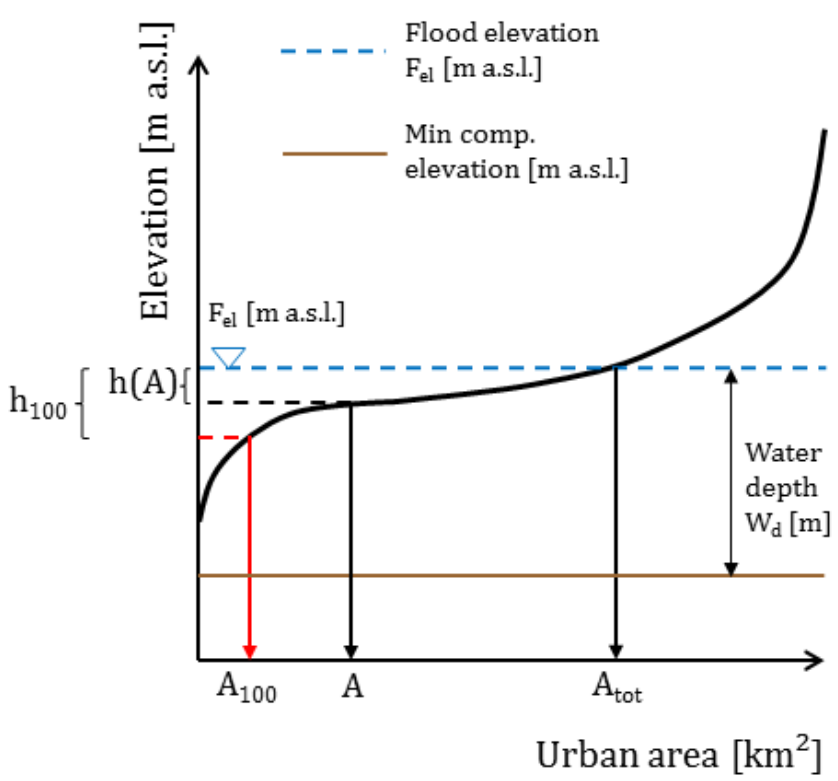

Figure 1. Schematic representation of the combination of (a) Depth-damage and (b) Hypsometric Vulnerability Curves for estimating potential flood damages in urban areas.

\section{Flood risk evolution in the Po River floodplain}

\subsection{Study area}

The study area consists in the alluvial plain of the longest Italian river, the Po river (about $650 \mathrm{~km}$ from west to east in the North of Italy). It flows in the Northern part of Italy for about $650 \mathrm{~km}$. Its river basin is also the wider Italian catchment (about $71000 \mathrm{~km}^{2}$ ) and includes a large portion of the Emilia-Romagna, Lombardy, Piedmont, Veneto and Aosta Valley regions (see Fig. 2). This basin, and in particular the Pianura Padana, a flat and alluvial area located in the middle-lower part of the basin with an overall extent of around $46000 \mathrm{~km}^{2}$, represents one of the most developed and populated area of Italy: more than $45 \%$ of employed Italians live here producing almost $40 \%$ of the total Italian Gross Domestic Product (GDP) (Po River Basin Authority, AdB-Po, 2006; http://www.adbpo.it).

Figure 2 shows the current river configuration. The main embankment system extends for more than $2900 \mathrm{~km}$ and outside of it is located the "C-Buffer" area (blue polygons, with an overall extent of about $6100 \mathrm{~km}^{2}$ ). These are the areas that can be flooded in case of sudden and unpredictable failures of the embankment system or in case of flood event with a recurrence period higher than the one adopted for the design of the embankments (i.e. 200 year, AdB-Po, 1999). The "CBuffer" is divided into different compartments depending on the layout of natural and man-made structures (e.g. roads, embankments, rivers, etc.; see also Castellarin et al., 2011b).

\subsection{Available data}

The analysis refers to a set of various data collected from different sources:

- Land-use maps: The information, available for the CBuffer, is retrieved from aerial imagery available for 1954 (GAI-Gruppo Aereo Italiano and WWS flights) and 2008 (AGEA-2008). The resolution of these images is of about 150 and $75 \mathrm{~m}$, respectively, and they are classified referring to the standardized classes aggregation adopted by the CORINE (COoRdinated INformation on the Environment) project (European Environment Agency - EEA, 2007).

- Assets economic values: We use the economical present values of residential buildings retrieved from the Italian Revenue Agency (Agenzia delle Entrate - AE; http: //www.agenziaentrate.gov.it), that take into account, among others classifications, the overall economic wellbeing of the region.

- Topographic information: TINITALY/01 (Tarquini et al., 2007) represents the most accurate Digital Elevation Model (DEM) covering Italy. It has a horizontal resolution of $10 \mathrm{~m}$ and a high vertical accuracy (i.e. root mean square errors ranging from 0.8 to $6 \mathrm{~m}$ ).

\subsection{Reference inundation scenario}

We refer to an inundation scenario obtained by Castellarin et al. (2011a) using the UNET code, available as part of 


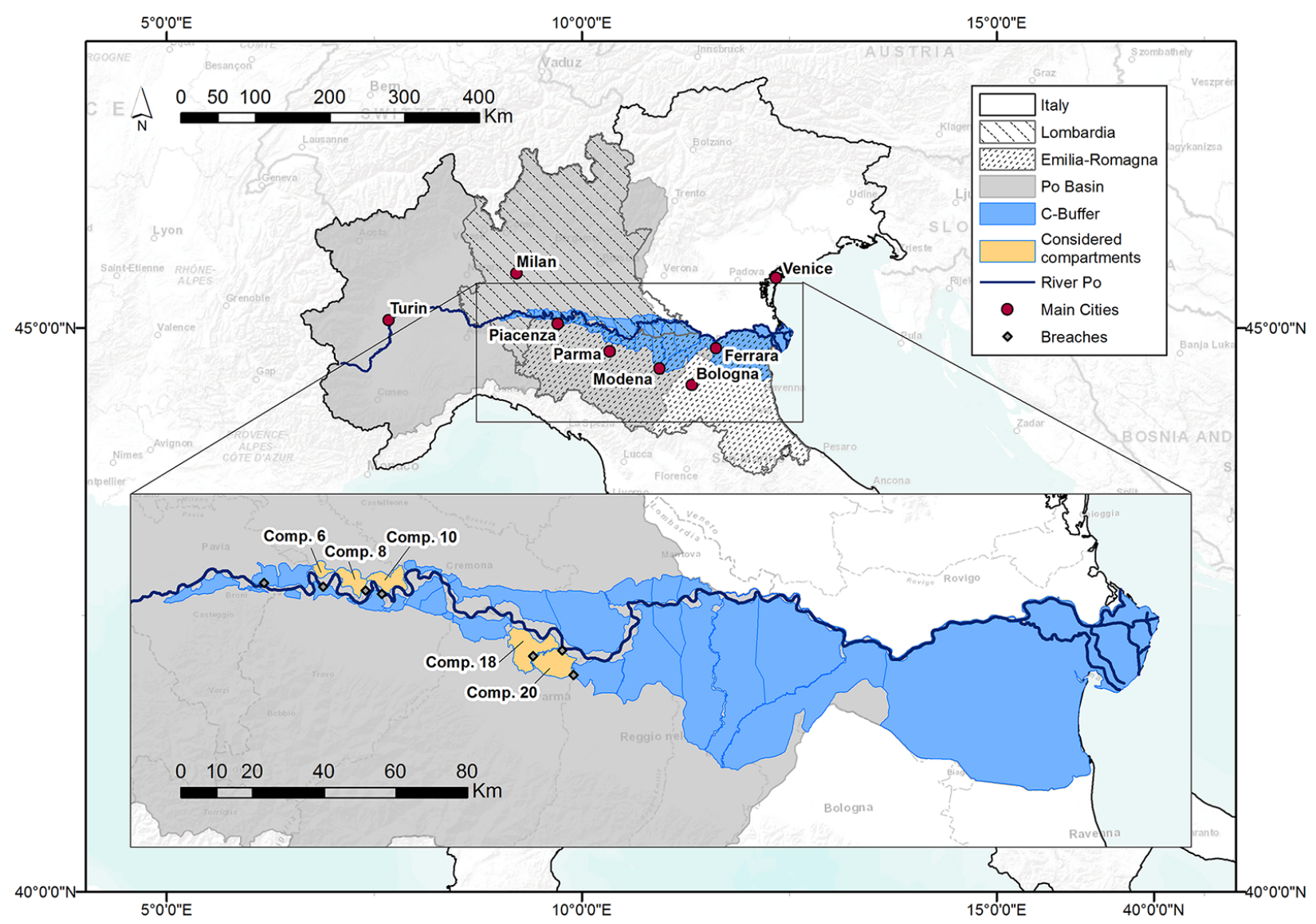

Figure 2. Study area: Po river basin and Regions of interests (Emilia-Romagna and Lombardy); the blue compartments (blue polygons) represent the area outside the levee system exposed to a residual flood risk (i.e. C-Buffer zone; AdB-Po, 1999).

the software package HEC-RAS, that numerically solves the Saint-Venant equations through an algorithm that uses a classical implicit four-point finite difference scheme (Castellarin et al., 2011a, and references therein). Referring to a 500-year return period event, the authors develop a quasitwo-dimensional (quasi-2-D) hydraulic model relative to the middle-lower reach of Po river, which describes the main channel by means of cross-sections retrieved from a detailed digital elevation model (LiDAR, with a spatial resolution of $2 \mathrm{~m})$. Storage areas connected to each other and/or to the main channel by means of weirs represent the dike-protected floodplains, mirroring an existing system of minor levees (see Castellarin et al., 2011b). The quasi-2-D model was calibrated referring to the historical flood event occurred in October 2000 (see Castellarin et al., 2011b for details). All the C-Buffer compartments are represented as storage areas connected to the main river, or to the dike-protected floodplains, by means of lateral structures that represent the main embankment crests. The behavior of the storage areas is controlled by volume-level curves by means of which the water level in case of inundation is computed as a function of the water volume exchanged with the main channel and/or adjacent storage areas. When the overtopping of the main embankments occurs, the model simulates the formation of breaches, whose width, depth and time of full development are retrieved from literature related to the Po river (see e.g. Govi and Turitto, 2000 and Castellarin et al., 2011a).

\subsection{Simplified flood risk assessment for different historical land-use scenarios}

Starting from the results of the reference inundation scenario, we examine the flood-risk evolution in the C-Buffer during the last 50 years. Even though we refer to land-use scenarios of different historical periods, 1954 and 2008, we consider the current geometry of the main embankment system. Our choice is justified because the aim of the study is to assess the role of the urbanization in the flood-risk evolution, independently of all other factors. By combining the HVCs computed for 1954 and 2008 with the maximum water inundation levels provided by the quasi-2-D model, we quantify the direct flood losses in urban areas for each flooded compartment according to the methodology outlined in Sect. 2.2. Among the available depth-damage curves, we refer to the damagecurve implemented in the Multi-Colored Manual (MCM; 
Table 1. Reference inundation scenario: flooded C-Buffer compartments according to the quasi-2-D model (see Castellarin et al., 2011a and Fig. 2).

\begin{tabular}{|c|c|c|c|c|c|c|}
\hline Compartment & $\begin{array}{r}\text { Maximum } \\
\text { water } \\
\text { depth } \\
{[\mathrm{m}]}\end{array}$ & $\begin{array}{r}\text { Total } \\
\text { overflow } \\
\text { volume } \\
{\left[10^{6} \mathrm{~m}^{3}\right]}\end{array}$ & $\begin{array}{r}\text { Flooded } \\
\text { urban area } \\
1954 \\
\mathrm{~A}_{\text {tot }}[\mathrm{ha}]\end{array}$ & $\begin{array}{r}\text { Flooded } \\
\text { urban area } \\
2008 \\
A_{\text {tot }}[\text { ha }]\end{array}$ & $\begin{array}{r}\text { Estimated } \\
\text { economic } \\
\text { damages } 1954 \\
\text { [B of today's euros] }\end{array}$ & $\begin{array}{r}\text { Estimated } \\
\text { economic } \\
\text { damages } 2008 \\
\text { [B of today's euros }\end{array}$ \\
\hline 6 & 6.8 & 60.95 & 22.17 & 31.55 & 0.17 & 0.24 \\
\hline 8 & 8.3 & 143.93 & 112.86 & 227.08 & 1.00 & 2.04 \\
\hline 10 & 7.1 & 80.77 & 101.46 & 143.36 & 0.47 & 0.64 \\
\hline 18 & 6.0 & 27.23 & 43.49 & 91.97 & 0.20 & 0.52 \\
\hline 20 & 5.5 & 204.96 & 143.43 & 450.89 & 1.37 & 3.90 \\
\hline 5 Compartments & - & $\sim 520$ & $\sim 420$ & $\sim 945$ & $\sim 3.20$ & $\sim 7.34$ \\
\hline
\end{tabular}

Table 2. Comparison between the quasi-2-D and fully-2-D models for the flooded compartments of interest.

\begin{tabular}{rrrrr}
\hline & $\begin{array}{r}\text { FAI for } \\
\text { flooded } \\
\text { urban areas } \\
1954[\%]\end{array}$ & $\begin{array}{r}\text { FAI for } \\
\text { flooded } \\
\text { urban areas } \\
2008[\%]\end{array}$ & $\begin{array}{r}\text { Difference in } \\
\text { damage } \\
\text { calculation } \\
1954[\%]\end{array}$ & $\begin{array}{r}\text { Difference in } \\
\text { damage } \\
\text { calculation } \\
2008[\%]\end{array}$ \\
\hline 6 & 91.4 & 89.0 & 2.90 & 3.44 \\
8 & 91.7 & 90.8 & 2.03 & 2.88 \\
10 & 69.6 & 71.1 & 42.92 & 40.47 \\
18 & 57.6 & 68.4 & 33.71 & 32.16 \\
20 & 93.6 & 87.8 & 2.41 & 2.59 \\
\hline
\end{tabular}

Penning-Roswell et al., 2005) that estimates at best the expected losses for residential buildings as a function of the local water depth.

Table 1 reports the maximum water depth and the total overflow volume simulated through the quasi-2-D model for each flooded compartment, together with the estimate of the extent of urban areas flooded in 1954 and 2008 and of the economic damages associated to the reference inundation scenario.

The choice of the compartments to be considered, among all the compartments flooded in the quasi-2-D model, has been done considering the five most representative compartments, from a morphologically and residential point of view.

In particular, because of urban expansion, the overall urban extent affected by the inundation scenario is equal to 420 ha in 1954 and 945 ha in 2008. Consequently, we calculate an overall damage associated with urban buildings equal to $\sim 3.2$ billions of today's euros in 1954 , that rose to $\sim 7.3$ billions of today's euros in 2008, more than twice as much relative to 1954 .

\subsection{Validation of the simplified approach}

We validate the proposed simplified approach against a series of simulations of the reference inundation scenario through the fully-2-D hydrodynamic model TELEMAC-2-D, which solves the 2-D shallow water Saint-Venant equations using the finite-element method within a computational mesh of triangular elements (see Galland et al., 1991 for details). In particular, TELEMAC-2-D is used to simulate the inundation dynamics in the flooded compartments of interest by using the overflowing flow-rates simulated with the quasi-2-D model as boundary conditions; we then compare the inundation extents simulated by TELEMAC-2-D with the corresponding extents retrieved from the quasi-2-D schematization. First, we quantify the agreement between flooded urban areas in 1954 and 2008 by means of the flood area index (FAI, see Falter et al., 2012) defined as

$\mathrm{FAI}=\frac{A}{A+B+C}$

where $A$ is the extent of the areas simulated as flooded by both models (blue areas in Fig. 3, lower panels), $B$ is the extent of the urban area that is flooded in the quasi-2-D schematization and dry according to the fully-2-D one (i.e. the simplified model overestimates the flooded areas simulated by the fully-2-D model; green areas in Fig. 3), while $C$ is the opposite of $B$ (i.e. the quasi-2-D model underestimates the flood extent simulated by the fully-2-D model; red areas in Fig. 3). Secondly, we calculate the total direct damage in each compartment by referring to the same damage curve considered in Sect. 2.2 and to the surface enveloping the simulated maximum water surface elevations resulting 


\section{Compartment 10}
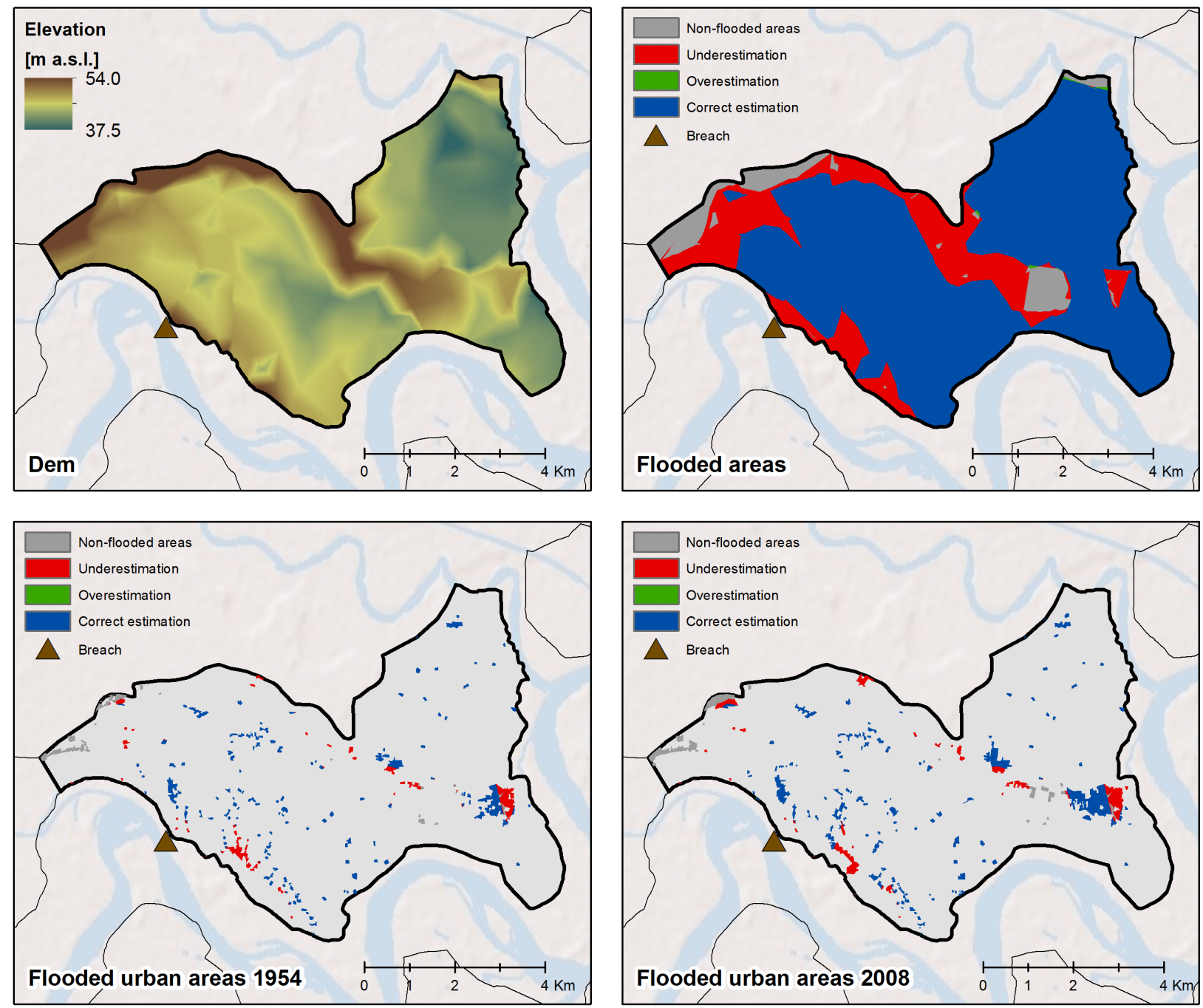

Figure 3. Compartment 10: DEM and comparison between the quasi-2-D and the fully-2-D model in terms of flooded areas (top panels) and flooded urban areas in 1954 and 2008 (bottom panels).

from TELEMAC-2-D and we compare these results with the outcomes of the simplified flood-risk evaluation.

Table 2 reports the FAI for flooded urban areas in 1954 and 2008 and for each compartment of interest, showing also the difference in terms of damage calculation for both years. The FAI index for flooded urban areas in 1954 and 2008 results very close to 1 (i.e. perfect agreement between simplified and traditional flood-risk assessment) for three out of 5 compartments, whereas the agreement is poorer for the remaining two compartments. The differences in damage calculations mirror the results in terms of FAI, with a minimum percentage difference of $\sim 2 \%$ for Compartment 8 and a maximum percentage difference higher than $40 \%$ for Compartment 10 , both in 1954 and 2008 (see Fig. 3).

\section{Discussion and conclusions}

We propose a simplified procedure (based on a quasi-2-D model and Hypsometric Vulnerability Curves, HVCs) for flood-risk assessment over large geographical areas and we compare its performances in estimating expected flood losses associated with two historical land-use scenarios with a traditional approach based on simulations from a fully-2-D hydrodynamic model. The analysis shows that the simplified approach is able of simulating the flooded areas in the compartments of interest with a reasonable accuracy. However, in two out of five study compartments we observe a significant difference in terms of simulated flood extent and floodrelated damages. Looking at Fig. 3, one can observe that this inaccuracy results from an inappropriate compartment delineation. In the specific case of compartment 10 , the simplified 
quasi-2-D model cannot correctly reproduce the flooding dynamics, since the inundation develops form the lowland portion of the compartment, regardless the position of the levee breach. On the contrary, the fully-2-D model ensures a correct reproduction of the flood dynamics given the topography of the study compartment. We expect that a more precise delineation of the compartments would lead to a higher accuracy of our procedure, which can thus be considered to be a valid simplified approach to assess the flood risk and its evolution in time over large geographical areas.

Acknowledgements. The study is part of the research activities carried out by the working group: Anthropogenic and Climatic Controls on WateR AvailabilitY (ACCuRAcY) of Panta Rhei - Everything Flows Change in Hydrology and Society (IAHS Scientific Decade 2013-2022).

\section{References}

AdB-Po: Progetto di Piano stralcio per l'Assetto Idro-geologico (PAI) - Interventi sulla rete idrografica e sui versanti (General Report, authored, edited and published by Po River Basin Authority), Parma, Italy, 351 pp., 1999 (in Italian).

AdB-Po: Caratteristiche del bacino del fiume Po e primo esame dell'impatto ambientale delle attività umane sulle risorse idriche, AdB-Po, Parma, Italy, 643 pp., available at: http://www.adbpo.it/download/bacino_Po/AdbPo_ Caratteristiche-bacino-Po_2006.pdf, 2006 (in Italian).

Barredo, J. I.: Normalised flood losses in Europe: 1970-2006, Nat. Hazards Earth Syst. Sci., 9, 97-104, doi:10.5194/nhess-9-972009, 2009.

Castellarin, A., Domeneghetti, A., and Brath, A.: Identifying robust large-scale flood risk mitigation strategies: A quasi-2-D hydraulic model as a tool for the Po river. Physics Phys. Chem. Earth., Parts A/B/C, 36, 299-308, doi:10.1016/j.pce.2011.02.008, 2011a.

Castellarin, A., Di Baldassarre, G., and Brath, A.: Floodplain management strategies for flood attenuation in the river Po, River Res. Appl., 27, 1037-1047. doi:10.1002/rra.1405, 2011 b.
Di Baldassarre, G., Kooy, M., Kemerink, J. S., and Brandimarte, L.: Towards understanding the dynamic behaviour of floodplains as human-water systems, Hydrol. Earth Syst. Sci., 17, 3235-3244, doi:10.5194/hess-17-3235-2013, 2013.

EEA (European Environmental Agency): CLC 2006 Thecnical guidlines, EEA, Copenhagen, 70 pp., ISSN 1725-2237, 2007.

Falter, D., Vorogushyn, S., Lhomme, J., Apel, H., Gouldby, B., and Merz, B.: Hydraulic model evaluation for largscale flood risk assessment, Hydrol. Process., 27, 1331-1340, doi:10.1002/hyp.9553, 2012.

Galland, J. C., Goutal, N., and Hervouet, J. M.: TELEMAC: a new numerical model for solving shallow water equations, Adv. Water Resour.. 14, 38-148, 1991.

Govi, M. and Turitto, O.: Casistica storica sui processi d'iterazione delle correnti di piena del Po con arginature e con elementi morfotopografici del territorio adiacente (Historical documentations about the processes of dam breaks in the River Po, in Italian), in: "Scienza e vita nel momento attuale", edited by: Istituto Lombardo Accademia di Scienza e Lettere, Milano, Italy, 105-160, 2000.

Kreibich, H., Seifert, I., Merz, B., and Thieken, A. H.: Development of FLEMOcs - A new model for the estimation of flood losses in companies, Hydrolog. Sci. J., 55, 1302-1314, 2010.

Penning-Rowsell, E., Johnson, C., Tunstall, S., Tapsell, S., Morris, J., Chatterton, J., and Green, C.: The benefits of flood and coastal risk management: a handbook of assessment techniques, Flood Hazard and Research Centre, Middlesex, 89 pp., ISBN1904750516, 2005.

Tarquini, S., Isola, I., Favalli, M., Mazzarini, F., Bisson, M., Pareschi, M. T., and Boschi, E.: TINITALY/01: a new Triangular Irregular Network of Italy, Ann. Geophys.-Italy, 50, 407-425, 2007.

Thieken, A. H., Olschewski, A., Kreibich, H., Kobsch, S., and Merz, B.: Development and evaluation of FLEMOps - a newFlood Loss Estimation MOdel for the private sector, edited by: Proverbs, D., Brebbia, C. A., and Penning-Rowsell, E., Flood Recovery, Innovation and Response I, WIT Press, 315-324, 2008.

Vorogushyn, S., Merz, B., Lindenschmidt, K.-E., and Apel, H.: A new methodology for flood hazard assessment considering dike breaches, Water Resour. Res., 46, 1-17, doi:10.1029/2009WR008475, 2010. 